\title{
COVID-19 and Food Insecurity: an Uneven Patchwork of Responses
}

\author{
Eliza W. Kinsey (D) • Dirk Kinsey • Andrew G. Rundle
}

Published online: 5 June 2020

(C) The New York Academy of Medicine 2020

Prior to the COVID-19 pandemic, an estimated $14 \%$ of families with children (13 million children) were food insecure, meaning they had limited or uncertain access to enough food for a healthy and active lifestyle [1]. With schools closed and families out of work, food insecurity rates are expected to skyrocket. Even shortterm food insecurity can have significant impacts on children's health, including poorer behavioral, emotional, and nutritional outcomes. Among children, food insecurity has been linked to increased risk of obesity [2], which can have long-term consequences for chronic disease morbidity [3, 4]. The COVID-19 pandemic complicates or even nullifies the complex strategies that families facing food insecurity use to feed themselves. In addition to increasing Supplemental Nutrition Assistance Program (SNAP) benefits, coordinated efforts to ensure food access are desperately needed.

In response to the rapid increase in food insecurity across the country, Congress' Families First Coronavirus Act (FFCA) made a number of provisions to expand federal nutrition assistance programs. One key provision enables states to issue pandemic electronic mealreplacement benefits (P-EBT) for households with chil-

E. W. Kinsey $(\bowtie) \cdot$ A. G. Rundle

Columbia University Mailman School of Public Health New

York, New York, USA

e-mail: edw2143@cumc.columbia.edu

D. Kinsey

Department of Geography and Urban Studies, Temple University, Philadelphia, USA dren eligible to receive free or reduced-price school meals, which amounts to a dollar value of roughly $\$ 114$ per child a month [5]. Local educational authorities are also enabled to use feeding practices from the USDA's summer meals programs to ensure children receive adequate nutrition during school closures. However, as noted elsewhere, federal guidelines for executing feeding programs safely amidst the COVID-19 outbreak are lacking, and many school districts do not have experience with summer feeding programs [6].

Additionally, states are allowed to increase SNAP allotments up to the maximum benefit amount as an emergency measure. However, at this time, 2.5 million households with children already receive the maximum benefit and states are not allowed to increase benefit levels beyond that maximum. In response, federal guidance to raise the SNAP benefit ceiling, as was done during the Great Recession under the American Reinvestment and Recovery Act, is critical for ensuring adequate nutrition and long-term health outcomes for millions of low-income children.

However, increasing SNAP benefits, while essential, will not address many of the barriers low-income families are facing in acquiring food during the pandemic. The complex and strategic food shopping patterns financially insecure families employ have been upended by the COVID-19 crisis [7]. Many low-income households visit multiple food stores in search of the most affordable products, often traveling long distances to acquire food [7]. For many urban households reliant on public transit or rideshare services, these strategic food shopping techniques are now much riskier. Group 
shopping trips, using one person's membership to club stores (e.g., Costco), are also risky given guidelines to maintain proper distance from others.

Many other common food insecurity coping strategies are also challenging amidst COVID-19 public health advisories and restrictions. Prior to this current crisis, food-insecure households have reported numerous techniques for making ends meet, including seeking resources from the charitable food sector (e.g., food pantries, soup kitchens) and relying on social networks for support [8]. Proper adherence to social distancing makes sharing meals with neighbors or family difficult, and congregate meals at senior centers and soup kitchens are all but impossible, particularly without clear guidance from health officials about how to serve meals safely.

Additionally, food hoarding, as has been widely documented across the country, leaves low-income families who cannot afford to buy in bulk at an extreme disadvantage when they find empty shelves at grocery stores [9]. For families who rely on SNAP and WIC, this is even more worrisome as their food shopping is already restricted to stores that accept the benefits and stock the approved food items. In addition, families typically run out of SNAP funds before the end of the monthly benefit cycle: on average, families spend more than $75 \%$ of their benefits within 2 weeks of receiving them [10]. This depletion of purchasing power at the end of the cycle creates pent up need for food shopping that is typically satisfied by large shopping trips immediately after the SNAP benefit cycle begins. Even with the larger benefit size for some families per the FFCA, SNAP dollars are unlikely to last the entire benefit period, and this cycle of surge buying by families using SNAP is likely to continue. However, this cyclic pattern of shopping may not align with food availability at stores.

As a grassroots response to these problems, many on social media have been advocating for households with more flexibility to hold off on shopping until later in the month after SNAP benefits have been disbursed, so as to leave food on the shelves for SNAP shoppers [11]. While commendable, many of those posting these recommendations to social media do not know that SNAP distribution schedules vary widely by state. To be effective, these efforts to stagger shopping to make room for SNAP households need federal or state coordination. To inform these efforts, we developed a web mapping tool that details national SNAP distribution dates by state (https://tinyurl. com/utxvj89).

Additionally, at the time the national emergency was declared in mid-March, SNAP recipients were prohibited from using their benefits to purchase foods online, with the exception of a pilot program in five states at a limited selection of food stores (Fig. 1). While this pilot has expanded rapidly during the pandemic, with 31 additional states added to the pilot as of May 20, 2020, rollout of the online purchasing technology may take several months in many states and eligible stores remain limited. This means many SNAP recipients still cannot order groceries to be delivered to their home and must shop in-person, thus putting themselves and their families at significantly greater risk and furthering the class and racial inequities already manifesting in the current crisis [12].

As local authorities await federal guidelines, many have implemented creative strategies of their own, resulting in an uneven patchwork of supports. Some school districts are delivering meals to students via school busses driving along their regular routes [13]. Other cities and states, including Philadelphia and South Carolina, are implementing graband-go food pick-up sites where families can obtain 5 days of food at one time $[6,14]$. In an attempt to provide a more centralized, efficient response to food insecurity, New York City has named a Food Czar to oversee all relief efforts in the city during the COVID-19 pandemic [15]. Despite innovative strategies to alleviate the impact of this crisis on the food security of children and families, COVID19 will exacerbate health disparities and have profound effects on the food and financial security of many in this country for years to come. 


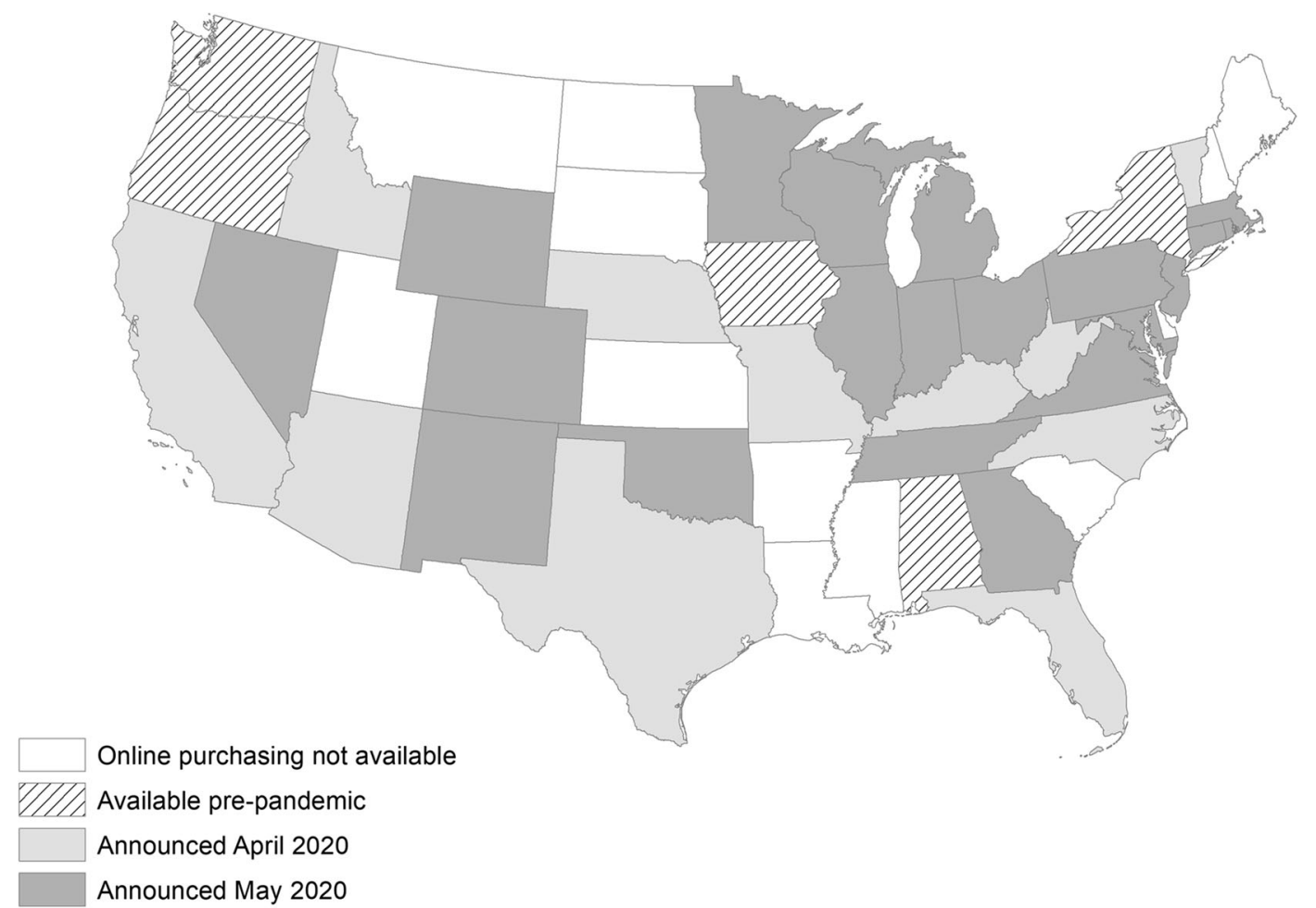

Fig. 1 State-level availability of SNAP online purchasing through USDA's SNAP Online Purchasing Pilot as of May 20, 2020

\section{References}

1. USDA ERS - Key statistics \& graphics. https://www.ers. usda.gov/topics/food-nutrition-assistance/food-security-inthe-us/key-statistics-graphics.aspx. Accessed Apr 6, 2020.

2. Metallinos-Katsaras E, Must A, Gorman K. A longitudinal study of food insecurity on obesity in preschool children. $J$ Acad Nutr Diet. 2012;112(12):1949-58. https://doi. org/10.1016/j.jand.2012.08.031.

3. Simmonds M, Burch J, Llewellyn A, et al. The use of measures of obesity in childhood for predicting obesity and the development of obesity-related diseases in adulthood: a systematic review and meta-analysis. Health Technol Assess (Winch Eng). 2015;19(43):1-336.

4. Rundle AG, Factor-Litvak P, Suglia SF, Susser ES, Kezios KL, Lovasi GS, et al. Tracking of obesity in childhood into adulthood: effects on body mass index and fat mass index at age 50. Child Obes. 2020;16(3):226-33. https://doi. org/10.1089/chi.2019.0185.

5. USDA, States Must Act Swiftly to Deliver Food Assistance Allowed by Families First Act. Center on Budget and Policy Priorities. https://www.cbpp.org/research/food- assistance/usda-states-must-act-swiftly-to-deliver-foodassistance-allowed-by-families. Published March 20, 2020. Accessed Apr 3, 2020.

6. Dunn CG, Kenney E, Fleischhacker SE, Bleich SN. Feeding low-income children during the Covid-19 pandemic. N Engl $J$ Med. 2020;0(0):null. doi:https://doi.org/10.1056 /NEJMp2005638

7. Cannuscio CC, Tappe K, Hillier A, Buttenheim A, Karpyn A, Glanz K. Urban food environments and residents' shopping behaviors. Am J Prev Med. 2013;45(5):606-14. https://doi.org/10.1016/j.amepre.2013.06.021.

8. Kinsey EW, Oberle M, Dupuis R, Cannuscio CC, Hillier A. Food and financial coping strategies during the monthly Supplemental Nutrition Assistance Program cycle. SSM Popul Health March 2019:100393. doi:https://doi. org/10.1016/j.ssmph.2019.100393

9. Grose J. Families scramble to find baby formula, diapers and wipes. The New York Times. https://www.nytimes. com/2020/03/30/parenting/coronavirus-baby-formulashortages-wipes-diapers.html. Published March 30, 2020. Accessed Apr 3, 2020.

10. Castner L, Henke J. Benefit redemption patterns in the Supplemental Nutrition Assistance Program. Alexandria, 
VA: U.S. Department of Agriculture, Food and Nutrition Service, Office of Research and Analysis; 2011.

11. This viral movement reminds everyone not to grocery shop until after April 3rd-here's why. https://money.yahoo. com/viral-movement-reminds-everyone-not-184116394. html?guce_referrer=aHR0cHM6Ly93 d3cuZ29vZ2 xlLmNvbS8\&guce_referrer_sig=AQAAAMk6sOL 1 huVhxKzrVIY47CxwVXWQfMn4vKfof0bKbuh3 pYDyIwv4Vo0rZxqMSemDZb-9sCBaaBFMvGm6w4Qi9 C63rWSqmyrQfG6I-hWsL9IUzKZZrwCfy405osMt7iBB2 OjKCiyNphp2t 7 craNrqUYj8Sjv0ZNH7kG91 CXPBIkB\&guccounter=2. Accessed Apr 6, 2020.

12. Online Purchasing Pilot| USDA-FNS. https://www.fns.usda. gov/snap/online-purchasing-pilot. Accessed Apr 3, 2020.

13. Schools race to feed students amid coronavirus closures. NPR.org. https://www.npr.org/2020/03/20/818300504 /schools-race-to-feed-students-amid-coronavirus-closures. Accessed Apr 3, 2020.

14. Where to find free, nutritious food during COVID-19 | Managing Director's Office. City of Philadelphia. https://www.phila.gov/2020-03-28-where-to-find-freenutritious-food-during-covid-19/. Accessed Apr 3, 2020.

15. De Blasio names "Food Czar" to combat impending hunger crisis with "mobilization we've never seen before." https://www.gothamgazette.com/city/9224-de-blasio-foodczar-impending-hunger-crisis-coronavirus-mobilization. Accessed Apr 3, 2020.

Publisher's Note Springer Nature remains neutral with regard to jurisdictional claims in published maps and institutional affiliations. 